\title{
Implementation Agreements Among Participants of OSINET
}

REVISED PAARCH 1987

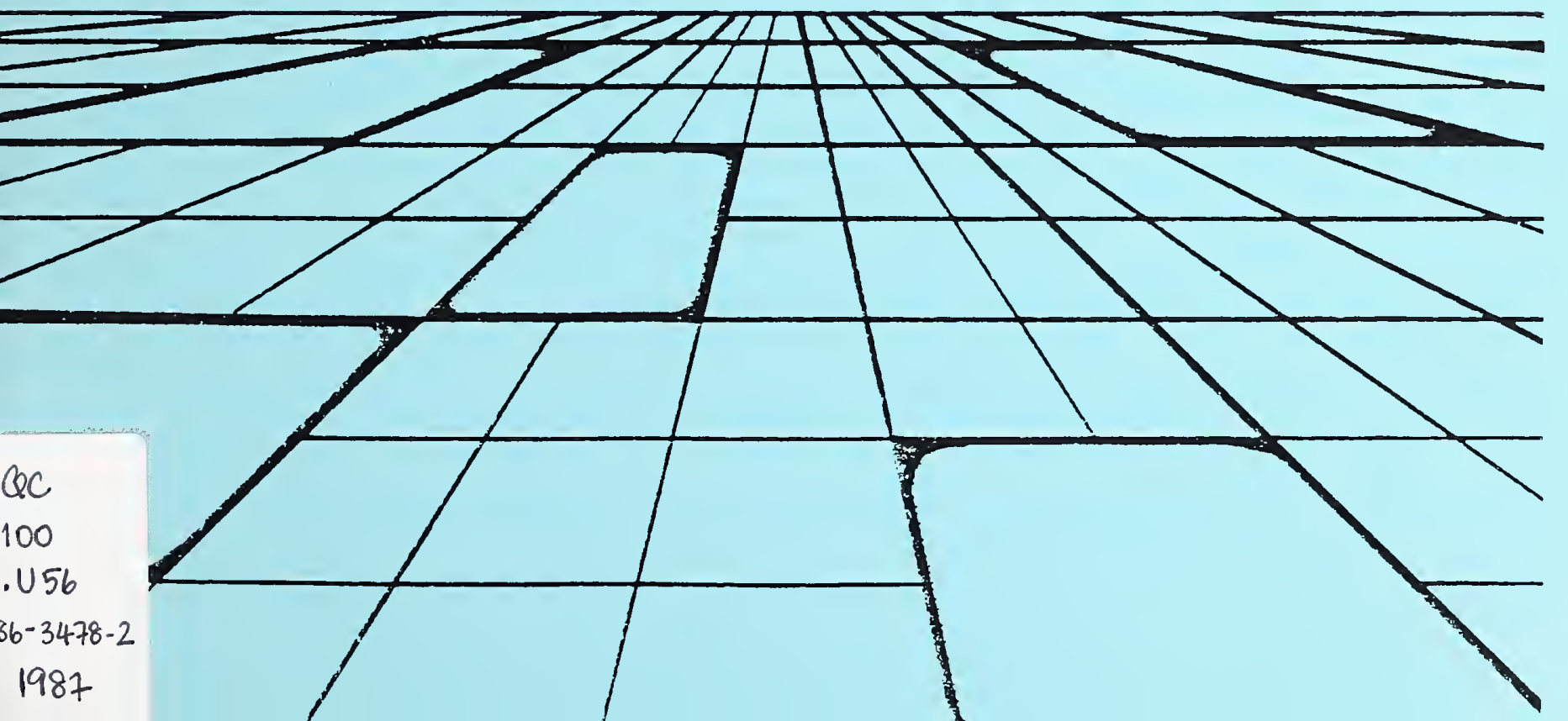



Table of Contents

1. GENERAL INFORMATION

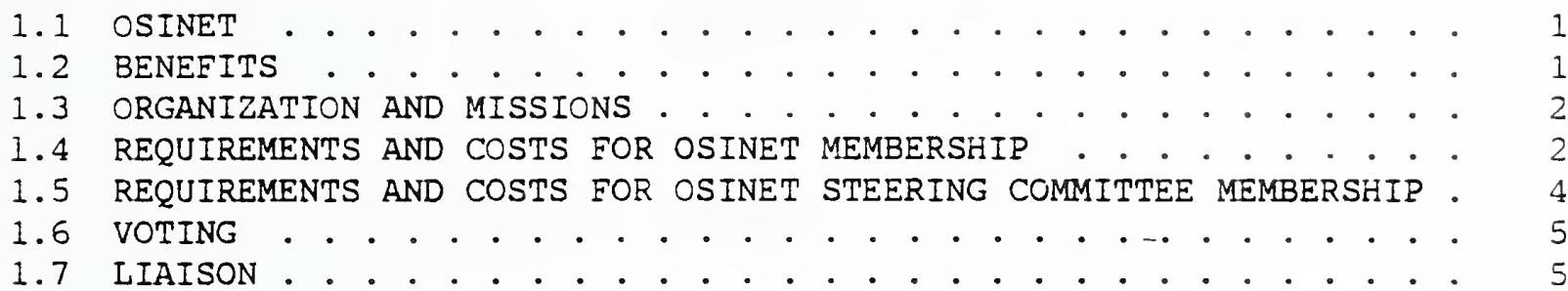

2. PROTOCOLS AND SERVICES . . . . . . . . . . . . . . . . . . . . . . . . 6

2.1 COMMONLY IMPLEMENTED PROTOCOLS AND SERVICES . . . . . . . . . . . 6

2.2 SPECIAL INTEREST PROTOCOLS AND SERVICES . . . . . . . . . . . . . 6

2.2 .1 X.400 . . . . . . . . . . . . . . . . . . . . . . . . . . 6

2.2 .2 ETAM . . . . . . . . . . . . . . . . . . . . . . . . 7

2.3 SOURCES OF IMPLEMENTATION AGREEMENTS . . . . . . . . . . . . . . . . . 7

3. X.25 SERVICES . . . . . . . . . . . . . . . . . . . . . . . . . . . . . 8

3.1 ACCUNET $(\mathrm{sm})$ PACKET SERVICE . . . . . . . . . . . . . . . . . . . 8

3.2 WANGPAC . . . . . . . . . . . . . . . . . . . . . . . . . . . . . 11

4. SITE CONFIGURATION, LOCATION, PROTOCOLS, AND POINT OF CONTACT . . . . 20

4.1 U.S. Department of Agriculture . . . . . . . . . . . . . . . . 20

4.2 AT\&T Communications . . . . . . . . . . . . . . . . . . . . 20

4.3 Boeing Computer Services . . . . . . . . . . . . . . . . 20

4.4 Charles River Data Systems . . . . . . . . . . . . . . . . . . . 21

4.5 Defense Communicarions Agency . . . . . . . . . . . . . . . . . . 21

4.6 Digital Equipment Corporation . . . . . . . . . . . . . . . . . . 21

4.7 General Motors . . . . . . . . . . . . . . . . . . . . 22

4.8 Hewlett Packard . . . . . . . . . . . . . . . . . . . . . 22

4.9 Honeywell Information Systems . . . . . . . . . . . . . . . . . 22

4.10 IBM . . . . . . . . . . . . . . . . . . . . . . . . . . . . . . 23

4.11 Industrial Networking, Inc. . . . . . . . . . . . . . . . . . . . 24

4.12 International Computers, Ltd. . . . . . . . . . . . . . . . . . 25

4.13 The MITRE Corporation . . . . . . . . . . . . . . . . . . . . 25

4.14 National Bureau of Standards . . . . . . . . . . . . . . . . . . 25

4.15 Department of Navy . . . . . . . . . . . . . . . . . . . . . 26

4.16 NCR Comten . . . . . . . . . . . . . . . . . . . . . . . . . . . 26

4.17 OMNICOM, InC. . . . . . . . . . . . . . . . . . . . . . . . . . . 27

$4.18 \operatorname{Retix}$. . . . . . . . . . . . . . . . . . . . . . . 27

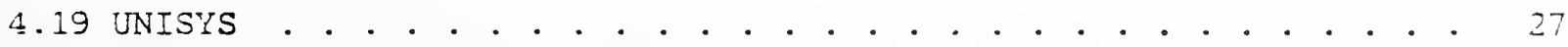

4.20 TASC . . . . . . . . . . . . . . . . . . . . . . . . 28

4.21 Wang. . . . . . . . . . . . . . . . . . . . . . . . . . . . . . . 23

4.22 The wollongong Group . . . . . . . . . . . . . . . . . . . . . . 29

5. PROGRAM OF WORK . . . . . . . . . . . . . . . . . . . . . . . . . 30 
5.1 INITIAL PROJECTS . . . . . . . . . . . . . . . . . . . . 30

5.1 .1 Initial Connectivity . . . . . . . . . . . . . . . 30

5.1 .2 NIC Services . . . . . . . . . . . . . . . . . 30

5.1.3 DOD Transition to the Use of OSI . . . . . . . . . 31

5.1.4 1987 Product Exhibition . . . . . . . . . . . . . . 31

5.1 .5 X.400 Message Handling Systems . . . . . . . . . . . . . 31

5.1 .6 Directory Services . . . . . . . . . . . . . . . . 32

6. POINTS OF CONTACT . . . . . . . . . . . . . . . . . . . . . . . . . . . 33

6.1 POINTS OF CONTACT FOR COMMITTEES . . . . . . . . . . . . . . . . 33

6.2 POINTS OF CONTACT FOR X.25 SERVICES . . . . . . . . . . . . . . . . . 33

REFERENCES AND BIBLIOGRAPHY • . . . . . . . . . . . . . . . . . . . . . . . 34

APPENDIX A: NETWORK ADDRESSING INFORMATION . . . . . . . . . . . . . . . . 37

APPENDIX B: FTAM INTEROPERABILITY TESTS . . . . . . . . . . . . . . . . . 38

READER RESPONSE FORM . . . . . . . . . . . . . . . . . . . . . . . . . 42 
This is a standing document that is revised several times a year following metings of the OSINET Technical and Steering committees.

\section{$\underline{1.1 \text { OSINET }}$}

The OSINET is an international resource that is being constructed to foster the development of Open Systems Interconnection. Specifically, it has the following objectives:

- Provide an open network environment for research and development by implementors and users of OSI protocols.

- Cooperative participant-to-participant testing.

- Assist in the development of test services.

- Conduct OSI research to provide results to ISO and CCITT.

- Companies shall not be discouraged from demonstrating products. No positive actions will be taken to demonstrate functionally enhanced prototype protocols as suggested by the NCC and AUTOFACT demonstrations.

The OSINET will be geographically distributed. Long-haul services will be provided by private and/or public subnetworks offering CCITT Recommendation X.25. Local environments will include standard LANs and other subnetworks.

\subsection{BENEEITS}

Perhaps the most beneficial aspect of OSINET comes about through collaboration of the participants so that there is 2 direct transfer to participating companies of the testing methods and sample software.

Companies may participate at a level of effort commensurate with corporate interests, upon satisfying the minimum requirements of participation.

Companies may use the OSINET to demonstrate OSI capabilities from their corporate location(s).

Companies may access the OSINET from conference exhibitions to reach a rich set of demonstrable applications.

Companies may participate in a wice variety of retwork-related experiments (as they choose) including stucies of protocol correctness and performance and network management. 


\subsection{ORGANIZATION AND MISSIONS}

The embodiment of OSINET consists of three entities:

- The OSINET network itself, comprised of subnetworks, intermediate systems, and end systems,

- An OSINET Steering Committee and,

- An OSINET Technical Committee.

The mission of OSINET is to facilitate the distributed development and testing of OSI based products by cooperating vendors and users of OSI.

The mission of the OSINET Steering Comittee is to establish and manage OSINET. The Steering Committee determines and approves all OSINET projects.

The mission of the Technical Committee is to carry out the technical work assigned by the steering Committee.

\subsection{REQUIREMENTS AND COSTS FOR OSINET MEMBERSHIP}

- A participating company may either:

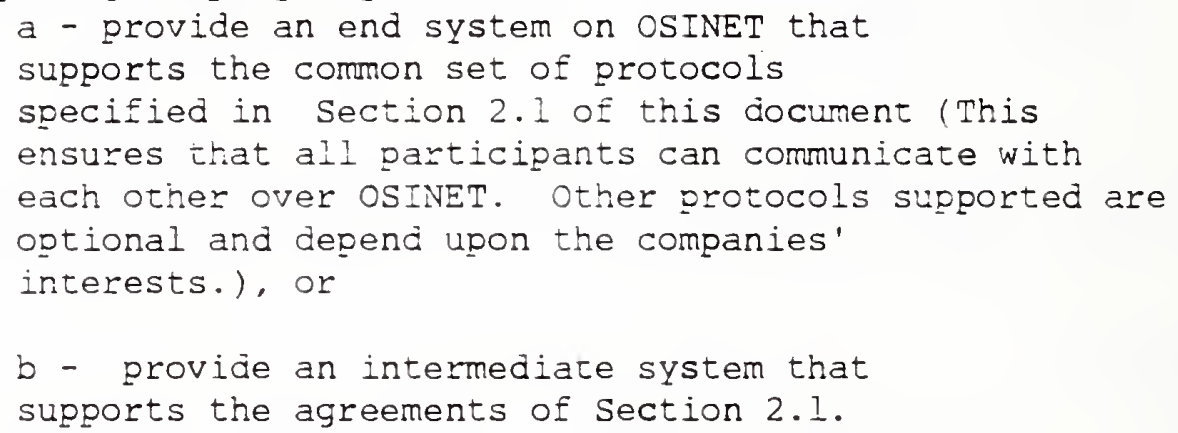

- To maintain eligibility in OSINET, companies must attend three of the most recent four meetings of the Implementors' Workshop. Else companies may be admitted to OSINET by the steering Committee on the basis of other significant participation.

- OSINET participants are expected to maintain a certain level of participation in OSINET projects.

o Participants shall maintain an implementation level reasonably current as determined by Steering Committee projects. 
- Personnel and other inhouse resources are determined by the participating company, after fulfilling obligations implied by the above items.

- Initial suppliers of the backbone X.25 service are AT\&T and Wang. Additional suppliers of X.25 service who wish to join OSINET are required to insure that OSINET connectivity is maintained. This can be accomplished by means of $\mathrm{X} .75$ links to existing X.25 suppliers, by providing an intermediate system that uses the routing and relaying functions of the CLNP to link to an existing X.25 network, or by arranging for another participant to provide the necessary intermediate system to link to an existing X.25 network.

- Costs associated with the installation, monthly charges, and traffic charges depend upon the X.25 service selected for an end or intermediate system that is directly attached to an X.25 service, and how that end or intermediate system is used. See Section 3, X.25 Services.

- Network Information Center (NIC) services, such as directory services, are being discussed. Should such services be adopted by the participants, NBS has agreed to serve as a NIC. Costs for development and operation of NIC services would be shared by companies using the services.

- A commitment, on company letterhead, to join OSINET must be sent to Jerry Mulvenna at NBS. Building 225, Room B217, Gaithersburg, MD, 20899. 


\subsection{REQUIREMENTS AND COSTS FOR OSINET STEERING COMMITTEE MEMBERSHIP}

- A company desiring to participate as a member of the OSINET Steering Committee must be an OSINET member in good standing as defined in section 1.4 of this document.

- The number of Steering Committee member companies shall be limited to 25. This number may be revised downward by action of the steering Committee, should this be necessary to achieve optimum function of the Comittee.

- Each company may send one representative to meetings. A management level representative is required. To provide needed continuity, consistent participation by the same representative is requested.

- Any company which has missed two out of three consecutive meetings of the steering Comittee will lose its steering Comittee membership at the next steering Committee meeting.

- Any company which is not a member in good standing of OSINET, as describea elsewhere in this document, will lose its membership on the steering Committee at the next steering Committee meeting.

Effective 1987, seats will be vacated by action of the committee at the last regular meeting of each calendar year. Voluntary release of company seats will be sought.

Effective 1987, a nominating comittee will be established at the last regular meeting of each year to propose candidates for membership at the next regular meeting.

- Effective 1988, applications for membership on the Steering Committee will be proposed annualiy by the nominating committee, for consideration at the first regular meeting of each calendar year.

- OSINET members and invited guests are permitted at the Steering Committee meetings. At its discretion, the steering comittee may choose to close its meetings, or limit participation to members. 
- No additional cost beyond those identified in section 1.4 will be charged to members of the Steering Committee.

\subsection{VOTING}

There is one vote allowed for each OSINET participating company. In order for a vote to be valid, the majority voting must vote yes or no. If the majority abstains, the vote does not count.

\subsection{LIAISON}

The Steering Committee shall liaise with other organizations on matters of policy and OSINET management. The Technical Committee shall liaise with other organizations on matters of technical interest. 


\section{PROTOCOLS AND SERVICES}

\subsection{COMMONLY IMPLEMENTED PROTOCOLS AND SERVICES}

Participants have agreed that all end systems on the OSINET shall be able to communicate with each other for purposes of OSINET administration and for access to common OSINET services. Having made that agreement, it is therefore necessary to agree to a common set of protocols to provide that communication service.

All end systems will support Iso connectionless internetwork protocol, the ISO transport class 4 protocol, and the ISO session protocol (basic combined subset with full duplex). These protocols will be supported from at least March 1986 through March 1989 by companies that are participating during that time period. The backbone subnetwork service is CCITT Recommendation X.25 presently provided by ATT's ACCUNET and WANG's WANGPAC. An end system may attach directly to either of these services. An end system may instead use the IEEE CSMA/CD or Token Bus or some other subnetwork and communicate through an intermediate system attached to either X.25 service. Implementation specifications for the above protocols are as defined in Implementation Agreements Among Implementors of OSI Protocols, NBSIR 86-3385.

The above protocols shall be used to access OSINET services. Services presently being studied include a bulletin board, a host name server, an application directory, a site contacts list, and test results from network management experiments.

The above agreement is not intenced to precluce experiments with, and tests and demonstrations of, implementations of other conforming sets of OSI protocols within the framework provided by OSINET. However, ail OSINET projects must be approved by the steering Commitzee.

\subsection{SPECIAL INTEREST PROTOCOLS AND SERVICES}

Aside from all participants being able to commuicate and access OSINET services, various subsets of participants are interested in other protocols and services. Two are identified below.

$2.2 .1 \times .400$

Participants wishing to use electronic mail on OSINET shall use MHF and ISO session (basic activity subset) when these protocols are included in NBSIR 863385. These protocols shall operate over the class 4 transport service as defined in NBSIR 86-3385.

2.2.1.1 Goals of OSINET Messace Project

1. To provide a basis for conducting interoperability testing of Iso standard (X.400) messaging implementations among OSINET participants. 
2. To verify that the X.400 functional standard defined by the NBS OSI Implementor's Workshop agreements is a complete and unambiguous specification for interoperation; and to provide appropriate feedback to that SIG.

3. To provide expanded communication among OSINET participants thru the use of electronic mail over OSINET.

4. To promote and publicize the use of X.400 messaging protocols.

5. To encourage the use of OSINET for communication among OSI Workshop participants.

\section{$\underline{2.2 .2 \quad \text { FTAM }}$}

Participants have agreed to support ISO FTAM. The version of FTAM that will be supported is specified in the May 1986 version of NBSIR 86-3385. The FTAM interoperability tests required to be run by each new system that joins OSINET are listed in Appendix B.

\subsection{SOURCES OF IMPLEMENTATION AGREEMENTS}

The long-haul services are presently provided by ACCUNET and WANGPAC. Since OSINET is intended to be international, it is expected that there will be other X.25 service providers in Europe and North America. It is hoped that the various X.25 services will evolve to a common version of CCITT Recommendation X.25, 1984 .

The NBS/OSI Workshop for Implementors of OSI Protocols is an open international forum comprised of computer manufacturers, semiconductor manufacturers, common carriers, and industry and government users. It was established for the purpose of reaching implementation agreements on evolving standards from IEEE, ISO, and CCITT.

The OSINET participants have elected to implement protocols for OSINET according to the implementation specifications developed in that workshop. See NBSIR 86-3385.

It is expected that other forums and organizations might produce implementation specifications for standard protocols. The OSINET will make use of such specifications where its members have a commercial or research interest in them and when they are reviewed and approved in an international, open forum, and projects making use of them have been approved by the Steering Committee. 


\subsection{ACCUNET (sm) Packet Service}

ACCUNET (sm) Packet Service, offered by AT\&T Communications, provides low delay/high throughput packetized data transmission with high reliability and availability. The service conforms to the DCE procedures set forth in the 1980 version of the CCITT Recommendation X.25. It supports the essential (E) services and facilities of X.25 as well as some additional (A) features.

Access to the service is provided separately by DATAPHONE (R) Digital Service (DDS), with the DDS Channel Service Unit (CSU), or a 4 wire analog point-topoint private line type 3002 channel. Digital access is supported at 4.8 , 9.6 , or $56 \mathrm{kbps}$; analog access is supported at 4.8 or $9.6 \mathrm{kbps}$ ( 9.6 kbps analog access may require conditioning). ACCUNET Packet service supports software controlled logical channels that enable multiple simultaneous calls over a single physical access line: 127 such calls at speeds of 4.8 and 9.6 kbps, and as many as 511 at 56 kbps.

Currently ACCUNET Packet Service is deployed in the following cities:

Akron
Albany
Albuquerque
Anaheim
Appleton
Atlanta
Austin
Baltimore
Birmingham
Boise
Buffalo
Cambridge
Camden
Cedar Rapids
Charlotte
Chattanooga
Chicago
Cincinnati
Cleveland
Colorado Springs
Columbia
Columbus
Dallas
Davenport
Dayton
Denver
Des Moines
Detroit
Eugene

Greenville
Harrisburg
Hartford
Houston
Huntsville
Indianapolis
Jackson
Jacksonville
Kalamazoo
Kansas City
Knoxville
Lansing
Lexington
Little Rock
Los Angeles
Louisville
Madison
Manchester
Memphis
Miami (OJUs)
Minneapolis
Mobile
Nashville
New Haven
New Orleans
New York City
Newark
Norfolk
Oakland

Philadelphia
Phoenix
Pittsburgh
Portland, ME
Portland, OR
Poughkeepsie
Providence
Raleigh
Reno
Richmond, VA
Roanoke
Rochester
Sacramento
St. Louis
Salinas
Salt Lake City
San Antonio
San Diego
San Francisco
Seattle
Shreveport
Spokane
Springfield, MA
Stockton
Syracuse
Tampa
Toledo
Tucson
Tulsa


Eresno

Et. Wayne

Grand Rapids

Greensboro oklahoma City

Omaha

Orlando

Peoria
Washington, D.C.

West Palm Beach

White Plains, N.Y.

Youngstown

In addition, ACCUNET Packet Service provides international access to other $\mathrm{X} .25$ packet networks in the following countries:

Australia
Belgium
Bermuda
Canada
France
Hong Kong

Australia

Belgium

Canada

Hong Kong
Ireland
Italy
Jamaica
Japan
Netherlands
Singapore

\author{
Spain \\ Sweden \\ Switzerland \\ United Kingdom \\ West Germany
}

ACCUNET Packet Service supports six different options for the assignment of DTE addresses to access lines. The most common of these is that an access line will have a single address assigned to it. Another option, which some participants may find useful, allows multiple addresses to be assignea to a single access line. Users may request from 1 to 10 blocks of 100 addresses to be assigned to their access line. More specific information on all six addressing options can be found in the AT\&T Technical Reference PUB 54010. Participants in OSINET should let their AT\&T Account Executive know which option meets their particular needs when ordering ACCUNET Packet Service.

ACCUNET Packet Service provides Virtual Call and Permanent Virtual Call services, both based on the logical channel conceot. By means of Virtual Call Service set-up/clearing procedures, logical channels can be established and terminated on demand. Permanent Virtual Cail Service eliminates the time required to set-up and clear each call by establishing permanent logical associations (not available for Virtual Calls) when the service is ordered. These remain in place until other service arrangements are ordered. For OSINET, AT\&T is reccmmending that all logical channels be established by Vircual Calls.

Both Virtual Call and Permanent Virtual Call services offer a wide range of software functions to increase control over circuit parameters, set-up, and functional attributes. Packet sizes of 128 and 256 octets as well as window sizes of 2 and 3 packets are supported.

Logical channels may be established as either two-way or one-way outgoing. For OSINET, AT\&T is recommending that logical channels are established oniy as two-way and, while it is possible to bar either incoming or outgoing calls on all logical channels, that these facilities not be provisioned.

Throughput class negotiation permits negotiation on a per call basis of the throughput classes for each direction of data transmission. Throughput classes up to and including 9600 bos are supported by ACCUNET Facket Service, Iimited only by access line speed. For OSINET, AT\&T is recommending that the throughput class negotiation facility be provisioned. 
Flow control parameter negotiation permits negotiation on a per call basis of the flow control parameters, window size and packet size, for each direction of data transmission. The default window size of 2 packets and packet size of 128 octets can be modified if both DTEs wish to use larger values and subscribe to this facility. For OSINET, AT\&T is recommending that the flow control parameter negotiation facility be provisioned.

The fast select facility allows DTEs to send up to 128 octets of data in the Call Request packet and receive up to 128 octets of user data from the called DTE in a Call Connected or a Clear Indication packet, if issued in direct response to the Call Request packet. The facility may be requested on a per call basis. The fast select acceptance facility authorizes the network to transmit to the DTE Incoming call packets which request the fast select racility. For OSINET, AT\&T is recommenaing that the fast select acceptance be provisioned.

Table 1 lists performance parameters and typical values which may be encountered by users of ACCUNET Packet Service. These performance parameters and typical values are published by AT\&T Comunications as a guide for the designers, manufacturers, consultants, and suppliers of systems and equipment which would connect to the X.25 interface. The performance values are based on design objectives and reflect typical network performance from one X.25 packet switch interface to another X.25 packet switch interface. As such, these values do not reflect delays associated with access lines to/from the packet switch. They are typical, but are not meant to imply a guarantee of quality or grade of service.

Aäitional information is available in the following AT\&T Commnications Technical References:

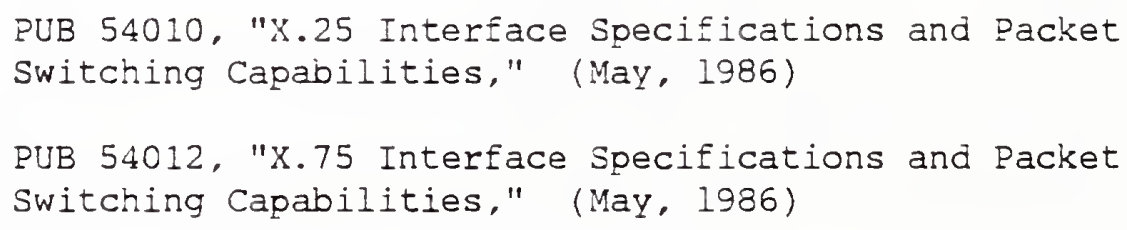

They are available from:

\author{
AT\&T Customer Information Center \\ Commercial Sales Rep. \\ P. O. Box 1990111202 \\ Indianapolis, IN 46219 \\ 1-800-432-6600 (Operator 101)
}

TABLE 1

ACCUNET Packet Service Network Performance Specifications

THROUGHPUT Virtual Circuit Daca Transfer

Rate

95\% of Through-

put Class 
AVAILABILITY Scheduled hours of Service

Loss of Service

Meantime to Restore Service

Service Blocking

Call Set-up

Data Transfer Delay ( 40 octets)

MALFUNCTION Rate of Incorrect Packet

Restart Rate
24 hours/day

7 days/week

8 hours per interface per year

5 hours

(average)

Less than $1 \%$

480 ms (Average

Busy Hour)

$135 \mathrm{~ms}$ (Average

Busy Hour)

1 per 10 million packets sent

5 per interface per year

\subsection{NANGPAC}

The following information has been provided by WANG.

An Overview To WangPac

WangPac is a packet switching network service offered by Wang Information Service Corporation (WISC) a wholly owned subsidiary of Wang Laboratories, of Lowell. Massachusetts.

Implemented over 18 months ago to serve the internal worldwide data communications requirements of Wang Laboratories, WangPac is based on the international packet switching technology stancard of X.25. We support the common set of protocols OSINET requires.

Designed with excess capacity, Wang Laboratories currently uses less than 7\% of the network. It is this excess capacity that we are making available to CSINET lisers as well as our commercial customers. The current configuration of the network has more than 60 locations serving in excess of 200 hosts with 10,000 users. WangPac has increased its users productivity and has provided a cost effective means of centralized support anc controlled growth.

\section{Access Protocols}


WangPac currently supports the following non-X.25 access protocols.

3270

$2780 / 3780$

ASYNC

SNA

\section{Network Operations Center}

The NOC located in Lowell, Massachusetts, is the network's command center. Operators have the ability to perform remote diagnostics and performance analysis on lines and nodes in the network. When a problem develops, they coordinate and dispatch support and maintenance ensuring efficent network operations.

We have installed X.25 packet switching nodes in the following locations:

\section{WangPac Domestic/Foreign PSN Locations}

Atlanta, Georgia

Bloomfield, Michigan

Boston, Massachusetts

Brussels, Belgium

Burlington, Massachusetts

Culver City, California

Century City, California

Coral Gables, Florida

Chelmsford, Massachusetts

Chesapeake, Virginia

Cincinnati, Ohio

Dallas, Texas

Des Moines, Iowa

Englewood, Colorado

Farmington, Connecticut

Greensboro, North Carolina

Haverhill, Massachusetts

Hong Kong

Honolulu, Hawaii

Houston, Texas

Independence, Ohio

Limerick, Ireland

London, England

Lowell, Massachusetts

Lawrence, Massachusetts

Marina Del Ray, California
Methuen, Massachusetts

Newport Beach, California

New York City, New York

Oakbrook, Illinois

Oakland, California

Philadelphia, Pennsylvania

Phoenix, Arizona

Portland, Oregon

Princeton, New Jersey

Puerto Rico

Rochester, New York

Rockville, Maryland

Rolling Meadows, Illinois

Rosslyn, Virginia

Rutherford, New Jersey

Salt Lake City, Utah

San Diego, California

San Francisco, California

Seattle, Washington

Shaumberg, Illinois

Singapore

St. Louis, Missouri

Stanford, Connecticut

Sydney, Australia

Tampa, Florida

Tewsbury, Massachusetts

Wayne, Pennsylvania 


\section{INTERFACE SPECIFICATIONS AND PACKET SWITCHING ATTRIBUTES}

This section describes the X.25 interface protocol currently supported by WISC's WangPac packet switching network.

Recommendation X.25 [1] of the International Telegraph and Telephone Consultative Committee (CCITT) specifies the interface between Data Terminal Equipment (DTE) and Data Circuit Terminating Equipment (DCE) for terminals or hosts operating in packet mode on public data networks (PDNs). FIPS 100/Federal Standard 1041 [2] specifies the general use of X.25 for the United States government. This standard defines some choices left open in Recommendation X.25. WangPac follows procedures that are in compliance with FIPS 100/Fed. Std. 1041 in areas where Recommendation X.25 allows a choice.

\section{INTERFACE SPECIFICATIONS AND PACKET SWITCHING ATTRIBUTES}

The interface described in this document is compliant to the DCE procedures set forth in the 1980 version of CCITT Recommendation X.25 and FIPS 100/Fed. std. 1041 dated July 6, 1983.

This document provides information on the specific X.25 features currently supported including:

o.X.25 parameter values

- action taken in areas where Recommencation X.25 offers a choice

- unique features not presently in Recommendation X.25 of FIPS 100/Fed. Std. 1041

This document assumes the reader is familiar with CCITT Recommendation X.25 and FIPS 100/Fed. Std. 1041. Information contained within is meant to be used with the text of both of these documents.

The WangPac Network

WangPac provides a value added packet switched transport service between user interfaces. The WangPac network, (figure 2.1), consists of packet switching nodes (PSNs), packet assembler/disassemblers (PADs), interconnecting trunk lines, and packet switch access points for user connections. The user packet switch points can support access at 56kbps, 48kbps, 19.2kbps, 14.4kbps, $9.6 \mathrm{kbps}, 4.8 \mathrm{kbps}, 2.4 \mathrm{kbps}$, and $1.2 \mathrm{kbps}$.

WangPac network interface supports Levels 1, 2, and 3 of the DCE side of EIPS 100/Fed. Std. 1041 and 1980 CCITT Recommendation X.25 protocol for Virtual Call and Permanent Virtual Circuit Services.

Access to Public Data Networks 
Within the United States, WangPac supplies Virtual Call and Permanent Virtual Circuit Services between DTEs.

For foreign countries, Virtual Call services are provided to most public packet networks worldwide.

Outline of WangPac X.25 Packet Switch Interface Protocol

WangPac supports three physical interface standards: RS-232C, RS-449, and V.35 at clock rates form 1.2 to 56 kilobits per second (kbps).

The link level protocol supports the Link Access Procedure Balanced (LAPB) procedure.

WangPac packet level interface supports both Switch Virtual Call (SVC) and Permanent Virtual Circuit (PVC) services.

WangPac supports the standard default level attributes specified in CCITT Recommendation X.25 of 128 octets for maximum size of the user data field, modulo 8 packet sequence numbering, and packet level window size of 2 .

Most facilities designated by FIPS 100/Fed. Std. 1041 are supported by WangPac. In addition, WangPac provides Fast Select and Fast Select Acceptance support for virtual calls.

Additional facilities and capabilities are under consideration.

At the end of this section, there is a summary of wangPac's X.25 packet switch interface.

WangPac X.25 Packet Switch Interface Attributes

This section describes switched virtual call (SVC) service and permanent virtual circuit (PVC) service, network addressing, and self-test capability.

\section{SVC Service}

Sitch virtual call service procedures and formats are in accordance with those specified in CCITT Recommendation X.25 and FIPS 100/Fed. Std. 1041. SVC service provides:

- interface initialization

- call setup and clearing

- flow control

- sequenced data transfer. 
The capabilities described in section 5.1 hold true for permanent virtual circuits except for call setup and clearing. PVCs do no require calls. Facilities for PVCs are set at subscription time.

\section{Network Addressing}

Addresses are assigned to the user by the WangPac administration. The address format utilized is consistent with CCITT Recommendation X.121.

All addresses are 12 or 14 digits in length. The 14 digit length includes 2 digits for subaddressing.

Two types of addressing are supported, physical addressing and logical addressing.

Physical addressing allows the indentification of the exact endpoint the user wishes to reach.

Logical addressing allows referencing hosts by either their physical address or by one of more location-independent logical addresses. It also gives the host control over which of the logical addresses it can be accessed by (this is optional for the host machine to implement). The logical address is 7 digits long and is mapped by the network into a physical address. There may be multiple logical addresses assigned to a single physical address or multiple physical addresses with the same logical address. The network can also translate the logical adaress into a prysical adaress in the incoming call packet so the host sees only a physical adiress.

In the case of multiple physical addresses tied to a single logical address, there are three selection criteria that can be used:
o Ordered List:
this method selects the first active port always searching from the beginning of the list.
- Shortest Distance: using the list of all active ports, select the destination physical adaress with the shortest routing distance from the source.

o Round Robin:

select the first active port starting the search from the last successfully selected port. The list will be viewed as a circular list.

Note: only active physical ports can be selected and a logical address can only have one selection criteria associated with it.

\section{WangPac X.25 User Facility Suoport}

WangPac supoorts many of the facilities described in Recommendation X.25 and FIPS 100/Fed. Sta. 1041. Each section below describes a facility and the 
WangPac implementation.

\section{Closed User Group}

This facility is assigned by WangPac Administration. It allows DTEs to restrict outgoing and incoming access to a "group" of registered DTES. A DTE may belong to a single group or a number of groups.

Each group is assigned a two digit index number in the range of 00-99. DTEs will use the index number as part of the closed user group facility request to identify the particular closed user group associated with the call request. DTEs subscribed to only one CUG are not required to use the facility, WangPac will insert the facility into the call request packet automatically.

Throughput Class Negotiation

This facility permit.s negotiation on a per call basis of the throughput classes for data transmission. The throughput class requested in the call request packet is validated against the configured line speed. If the value requested is less than or equal to the line speed, the call is permitted, else the call is cleared.

The incoming call packet presents the DTE with the lesser of the calling DTE's requested value or the maximum throughput class for the called DTE. The value in the call connect packet must be less than or equal to the value requested in the call request packet.

The negotiated value must be the same for both directions. There is no guarantee of performance with througnput negotiation.

\section{Flow Control Negotiation}

This facility permits on a per call basis, negotiation of packet and window sizes. The values negotiated must be the same in both directions. WangPac defaults have a packet size of 128 octets and window size of 2 . If no packet size or window size is requested. these values are in effect.

WangPac allows packets sizes of $16,32,64,128,256,512$, and 1024 octets to be negotiated.

Window sizes of $1-7$ may be negotiated.

One Way Logical Channel outgoing

This facility is set by WangPac Administration. It allows a user to set aside a logical channel or channels to be used exclusively for outgoing calls. The user must specify the logical channel(s) that will be used for this service. 
This facility is set by WangPac Administration. It allows a user to set aside a logical channel or channels to be used exclusively for incoming calls. The user must specify the logical channel(s) that will be used for this service.

\section{Outgoing Calls Barred}

This facility is set by WangPac Administration. It prevents outgoing calis to be made for a DTE. This is equivalent to specifying all logical channels as being One Way Logical Channels Incomi

\section{Incoming Calls Barred}

This facility is set by WangPac Administration. It prevents incoming calls to be made fo a DTE. This is equivalent to specifying all logical channels as being One Way Logical Channels Outgoing.

\section{Fast Select}

The DTE may request this facility on a per call basis in the call request packet. The calling DTE is allowed up to 1024 octets of user data to be included in the call request packet and up to 1024 octets of user data to be received in the call connected packet or clear indication packet (if issued in direct response to the call request) from the called DTE. This facility must be requested by the subscriber, it is not activated in the standard configuration.

\section{Fast Select Acceptance}

This facility is set by WangPac Administration. It empowers WangPac to transmit to the DTE incoming call packets which contain the fast select facility. If a DTE does not subscribe to this facility, WangPac will not pass on the DTE incoming call packets with the fast select facility. This facility must be requested by the subscriber, it is not activated in the standard configuration.

This facility is set by WangPac Administration. It allows a user to make call request containing the reverse charging facility. If the access port is not configured for reverse charging and a DTE issues a call request packet with the reverse charging facility, the call is cleared. This facility must be requested by the subscriber, it is not activated in the standard configuration.

\section{Reverse Charging Acceptance}

This facility is set by WangPac Administration. It authorizes WangFac to transmit to the DTE incoming cali packets which contain the reverse charging facility. If a DTE does not subscribe to this facility, wangPac will clear ali calls destined to the DTE that contain the reverse charging facility. 
This facility must be requested by the subscriber, it is not activated in the standard configuration.

\section{RPOA Selection}

The DTE may request this facility on a per call basis. It allows the calling $D T E$, in the call request packet, to specify the particular Recognized Private Operating Agency (RPOA) transit network through which the call is to be routed.

\section{Reverse Charging}

\section{SUMMARY OF WANGPAC INTERFACE FEATURES}

\section{Feature}

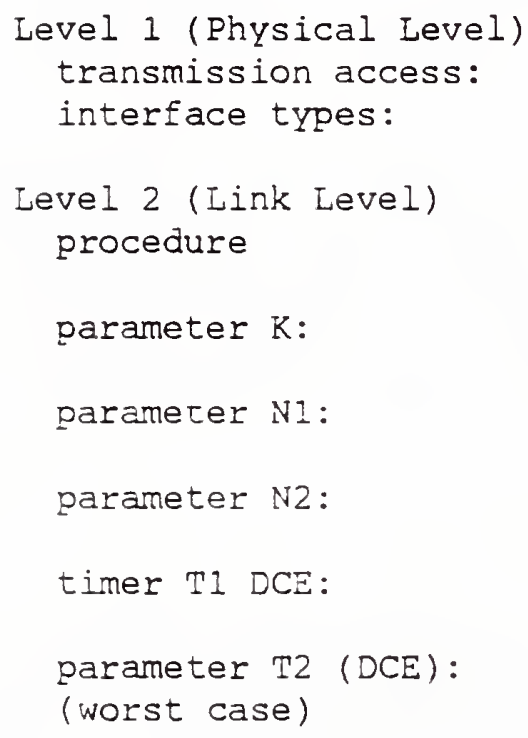

sequencing:

Level 3 (Packet Level)

services:

packet types:

\# of logical channels per

DTE (default)

\section{Description}

$1.2,2.4,4.8,9.6,14.4,19.2$. 56 kbos RS232-C, RS $-449, . V .35$

LAPB

7 default, 1-6 optional

8248 bits

20 cefault, 1-200 optional

less than or equal to 3 seconds

less than or equal to $.5 \mathrm{sec}$ for speeds less than or equal to 19.2 kbps less than or equal to $.25 \mathrm{sec}$ for speeds greater than 19.2 kips

modulo 8

virtual call and permanent

virtual circuit

all basic packets plus diagnostic, interrupt and interrupt confirm packets

10 (acjitional logical channels available at acditional cost) 
LCN range:

user data field:

packet sequencing:

address format
$0-4095$

octet aligned

modulo 8

14 digits
VC user facilities*

Recommendation X.25 and FIPS 100

Closed User Group (CUG): CUG with Incoming Access:

CUG with Outgoing Access:

Bilateral CUG:

Bilateral CUG with Outgoing Access:

Throughput Class Negotiation:

Flow Control Negotiation packet size:

octets

$$
\text { window size: }
$$

one Way Logical Channel Outgoing:

One Way Logical Channel Incoming:

Incoming Calls Barred:

Outgoing Calls Barred:

Fast Select:

Fast Select Acceptance:

Reverse Charging:

Reverse Charging Acceptance:

RPOA Selection:

\section{Support Provided}

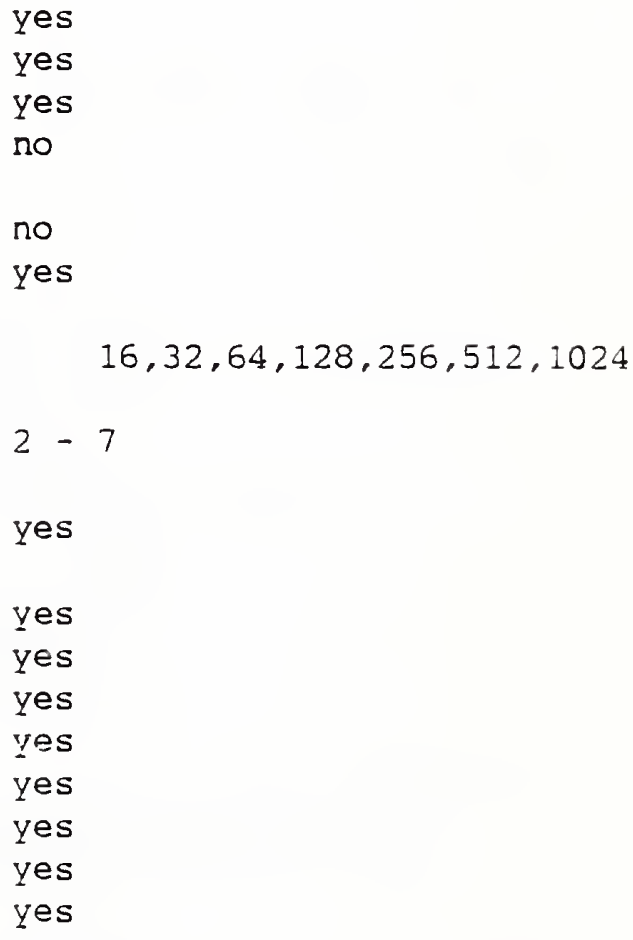

* Facilities that apply to both virtual call and permanent virtual circuics are available to both if supported. 
4. SITE CONFIGURATION, LOCATION, PROTOCOLS, AND POINT OF CONTACT

INFORMATION FOR OSINET PARTICIPANTS

This section provides the information suggested by the title. Each participating company is expected to complete their subsection.

\subsection{U.S. Department of Agriculture}

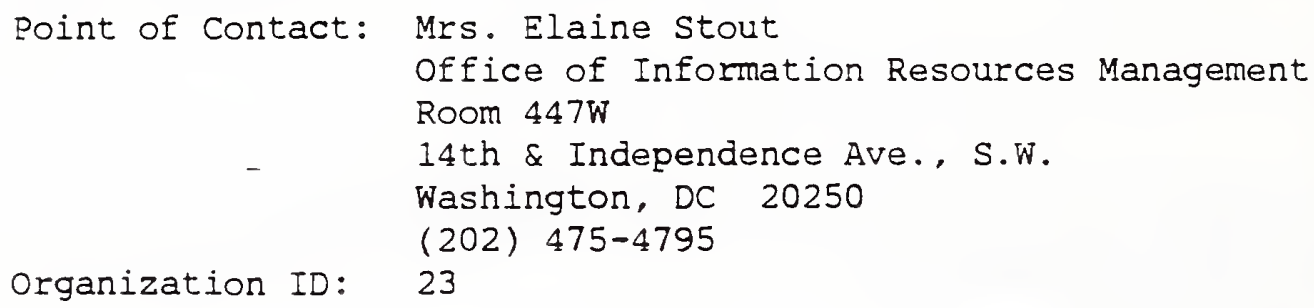

\subsection{AT\&T Communications}

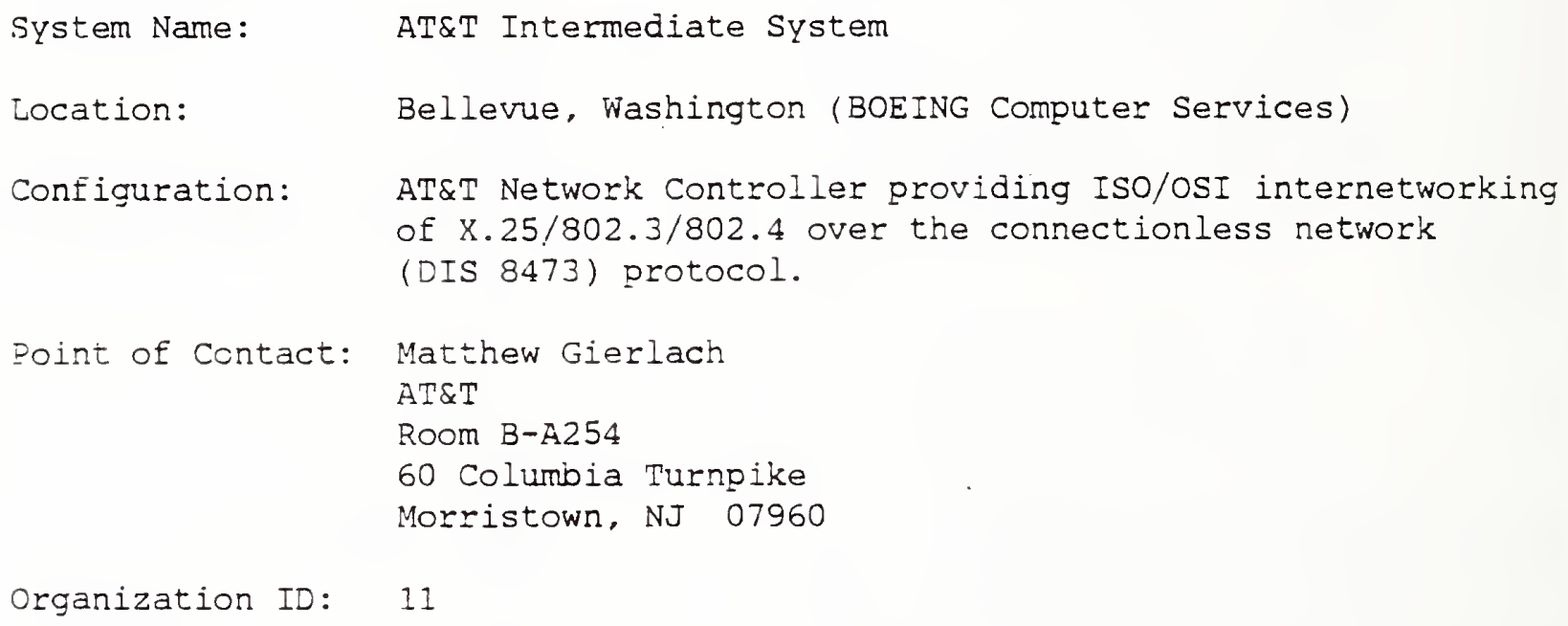

\subsection{Boeing Computer Services}

Location:

Configuration:

Protocols:

of Attachment:
Bellevue, Washington

AT\&T X.25 router to 802.3 and 802.4 modes

FTAM (AUTOFACT), BCS Session

(Eull Duplex), Transport

(Class 4), Internet Protocol Router

31342067081001 
Point of Contact: Les Kerr

P.O. Box 24346

Seattle, WA 98124-0346

(206) 763-5868

Organization ID: 12

\subsection{Charles River Data Systems}

Point of Contact: Eric Spiewak

983 Concord St.

Framingham, MA 01701

(617) 626-1000

Organization ID: 13

4.5 Defense Communications Agency

Point of Contact: Martin Thompson

DCEC

1860 Wiehle Avenue

Reston, VA 22090

Organization ID: 22

4.6 Digital Equipment Corporation

Subnet:

Access lines:

Configuration:

Protocols:

Point of Contact:
British Telecom's PSS service giving access to AT\&T's Accunet via X.75

1 (a) $9.6 \mathrm{~kb}$

micro-VAX II

FTAM, Full Session, CLNP/X.25-80, X.25-80, VARCRLF, and UNDEF presentation contexts.

Richard BenweII

REO2-G/M9

Digital Park

Imperial Way

Reading

$+44-734-868711$

Organization ID: 14 
4.7 General Motors

Point of Contact: Gary Workman

APMES A/MD-39

30300 Mound Rd.

Warren, MI 48090

(313/575-0632

Organzation ID: 15

4.8 Hew lett Packard

Configuration:

HP 1000

Protocols:

FTAM, CASE, Session (BCS full duplex), Transport Class 4 and end-node connectionless IP

Point of Contact:

Mary E. Ryan

Rnd R3NF

8000 Foothills Blvd.

Roseville, CA 95678

916/786-8000 x4519

Organization ID: 16

4.9 Honeywe11 Information Systems

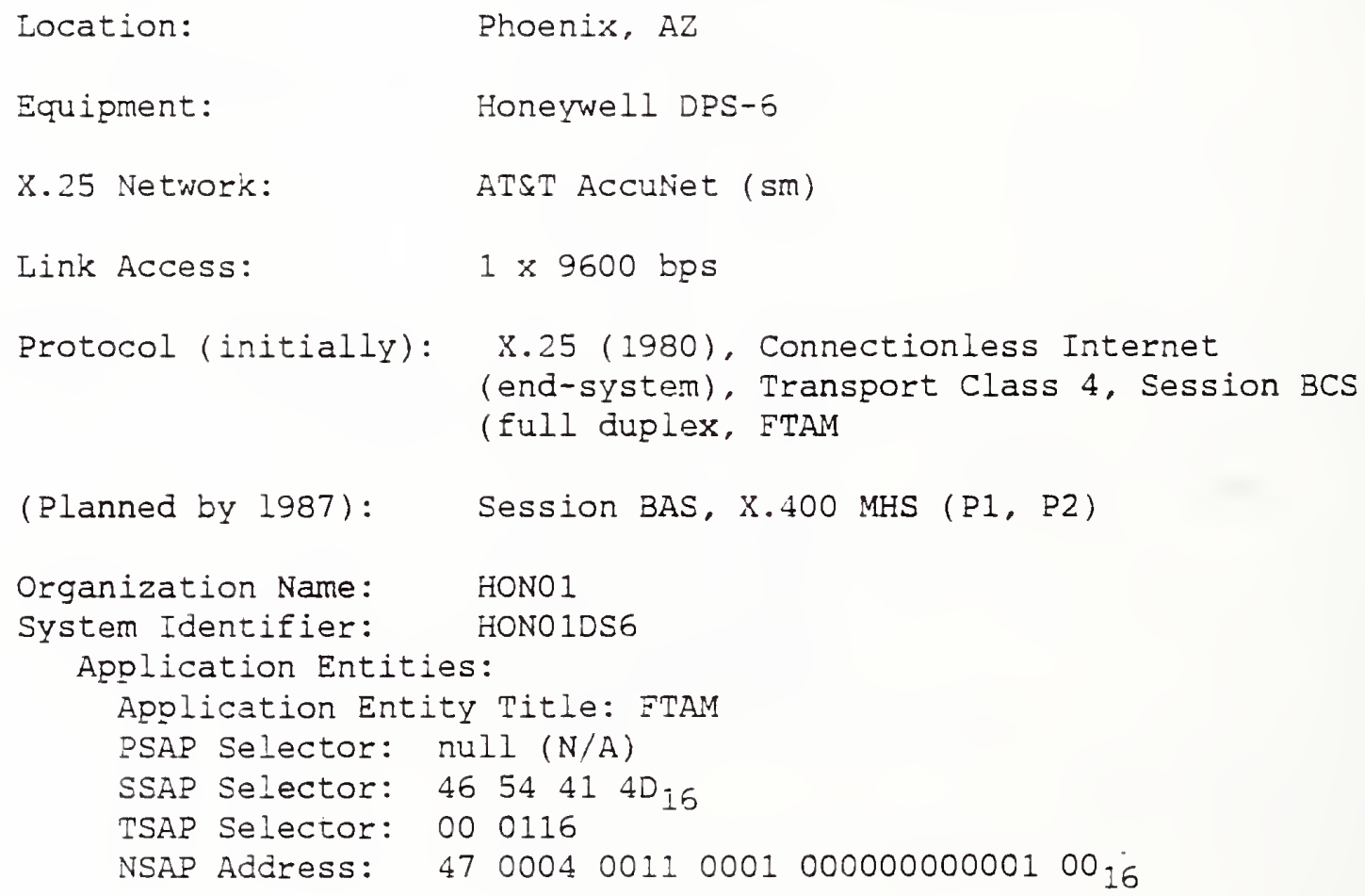




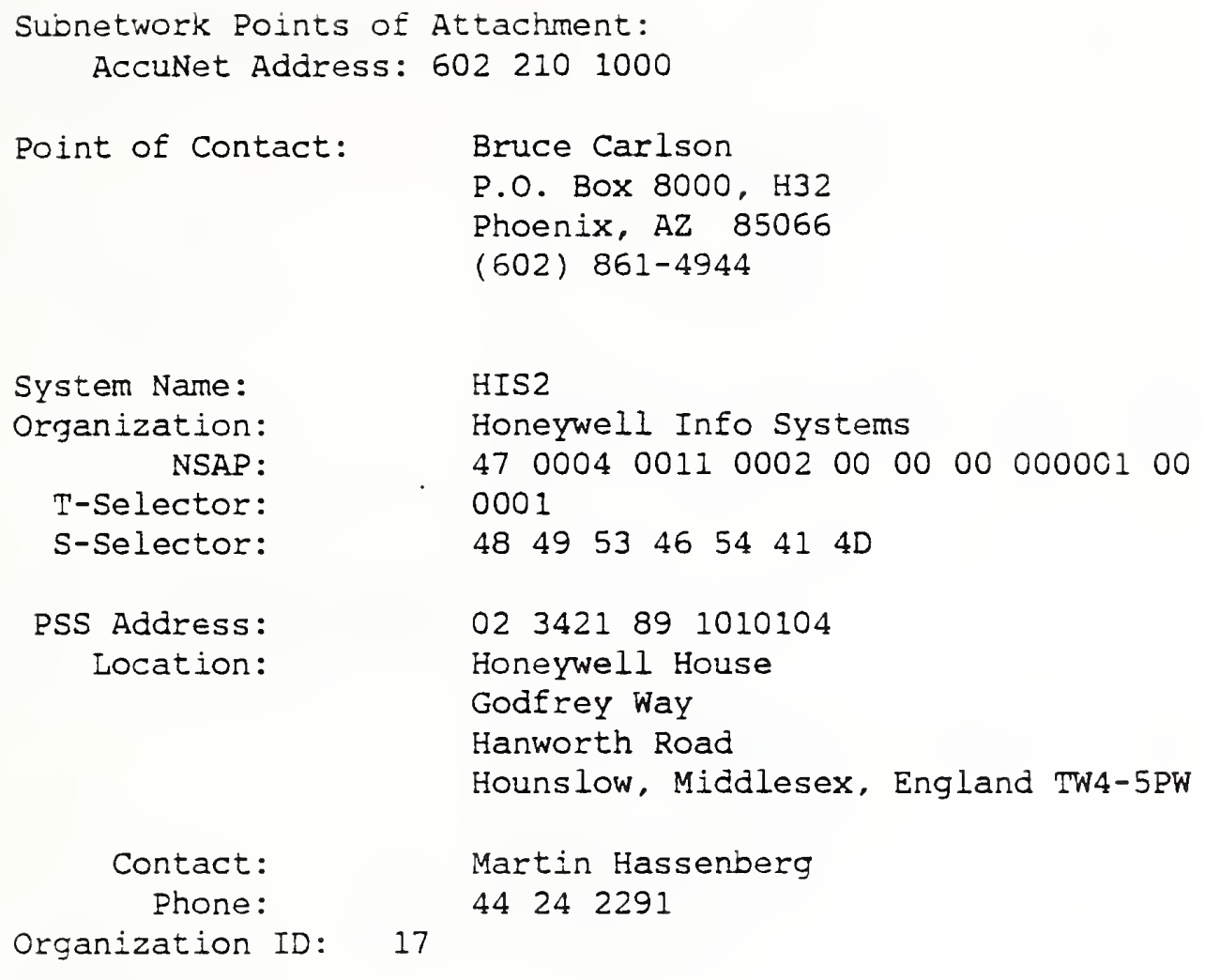

4.10 IBM

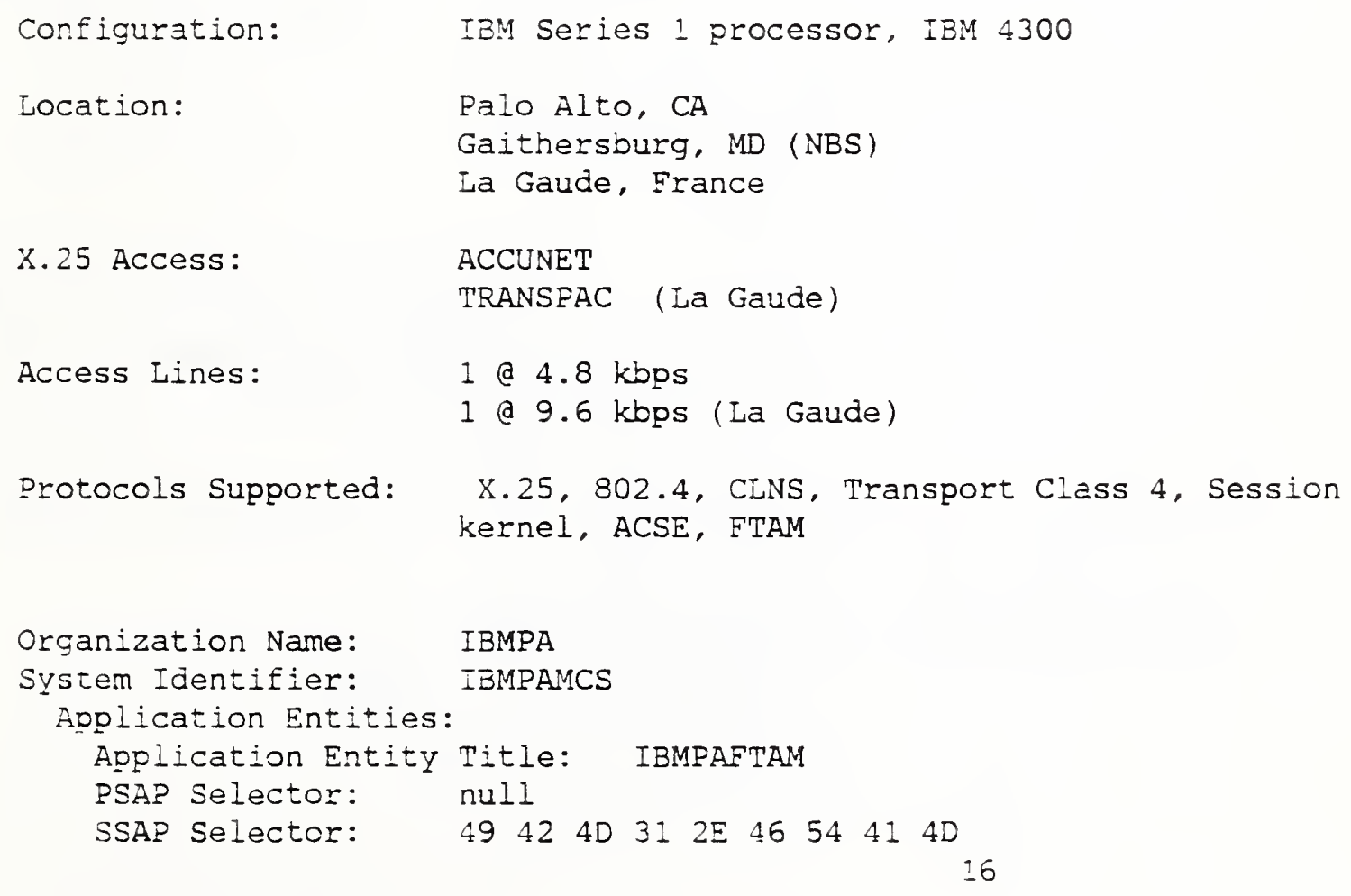


TSAP Selector: 0001

NSAP Selector: $\quad 4700040001000141525710620000$

Subnetwork Points of Attachment:

ACCUNET Address: 4152571062

Organization Name: IBMLG

System Identifier: IBMLGMCS

Application Entities:

Application Entity Title: IBMLGFTAM

PSAP Selector: null

SSAP Selector: $\quad 4942 \quad 4 D \quad 32 \quad 2 E \quad 46 \quad 54 \quad 414 D$

TSAP Selector: 0001

NSAP Selector: $\quad 4700040001000220800604176800$

Subnetwork Points of Attachment:

ACCUNET Address: 208006041798

Point of Contact: Edward C. Strum

1501 California Ave., N.w.

Palo Alto, CA 94303-0828

(415) 855-3996

Henri Chorosz

$0113393 \quad 585772$

Organization ID: 1

4.11 Industrial Networking, Inc.

Location:

X.25 Attachment:

Configuration:

Protocols:

Access Lines:

Point of Contact:

Organization ID: 7
Southfield, MI

ACCUNET

a) VAX 11/750 running VMS and Eunice operating systems

b) IEEE 802.4 LAN Attachments

As specified in SNA 85-1

19600 Baud

Richard Parenteau

Manager, Software Engineering

23999 Northwestern Highway

Suite 100

Southfield, MI 48075

(313) $354-4616$ 
4.12 International Computers, Ltd.

Subnet:

British Telecom's PSS Service giving access to AT\&T Accunet via X.75

Access Lines:

1 a $4.8 \mathrm{~Kb}$

Configuration:

PERQ running PNX

Protocols:

Internet

Transport classes $0,2,3,4$

Session (full)

FTAM

NSAP: 4700040002000123427820010500

SNPA: 234278200105 (PSS)

Point of Contact:

J.R. Cadwallader

Manager, Network Technology

Technical Directorate

Westfields West Avenue

Kidsgrove Stoke-on-Trent ST7 ITL

United Kingdom

(0782) 29681

Organization ID: 2

\subsection{The MITRE Corporation}

Point of Contact:

Organization ID:

24
Claude E. LaBarre

Burlington, MA 01730

(617) 271-8507

\subsection{National Bureau of Standards}

X.25 attachment:

ACCUNET and WANGPAC

Location:

Gaithersburg, MD

Network Configuration:

Protocols: a) VAX/780 intermediate and end system

b) IBM Series $1^{\prime}$ 's as end systems

c) IEEE 802.3 and 802.4 LAN attachments

d) correctness lab, performance lab, LAN lab, and multi-processing lab attachments via the LANs

as specified in NBSIR-86-3385. 


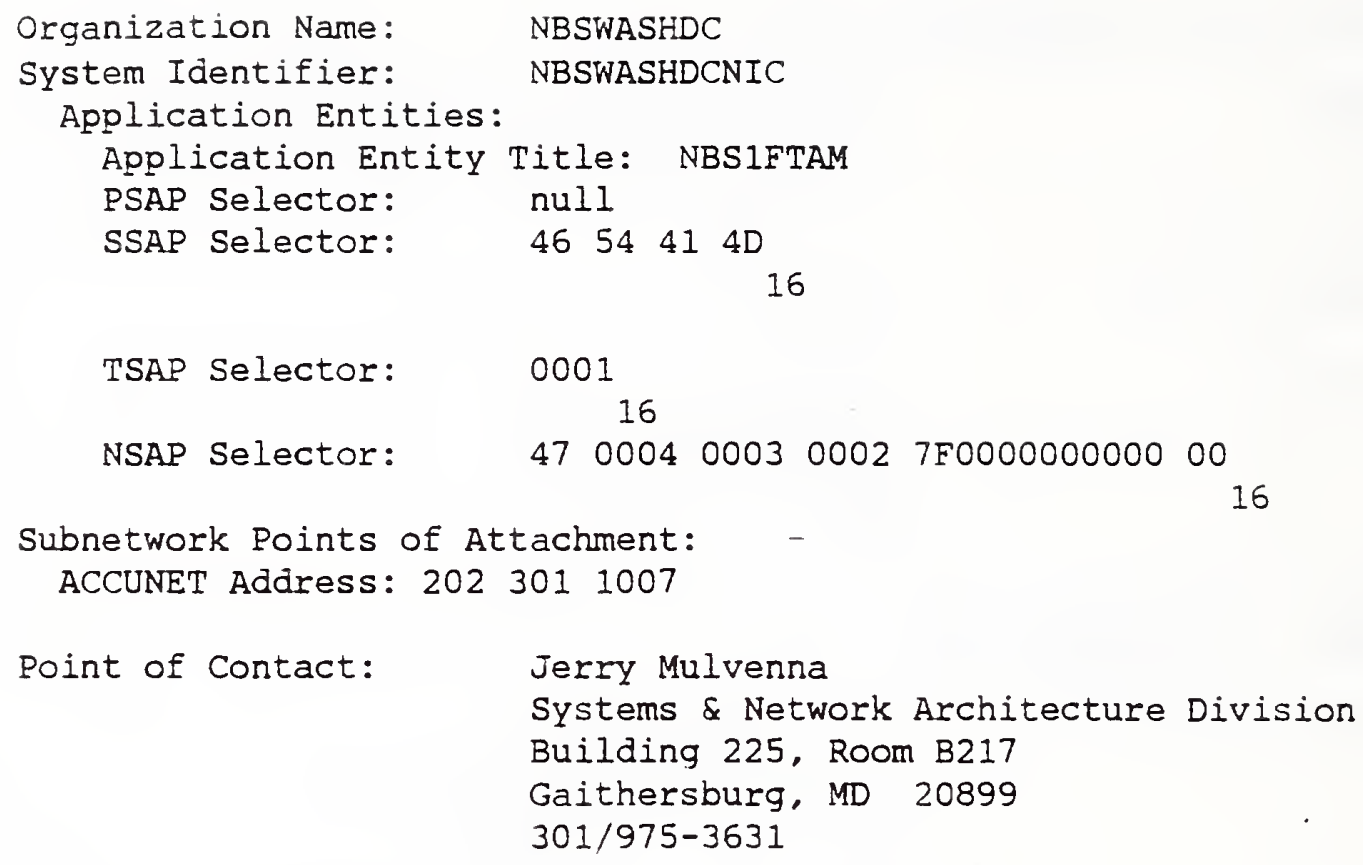

Organization ID: 3

\subsection{Department of Navy}

Point of Contact:

Dave Norem

NAVDAC, Code 32

Washington Navy Yard

Bldg. 218-2

Washington, DC 20374-1662

Organization ID: 20

4.16 NCR Comten

Configuration:

NCR Tower XP running UNIX System V (operating as an end system)

Location:

Minneapolis/St. Paul, MN

X.25 Access:

ACCUNET

Access Lines:

1 @ $9.6 \mathrm{kbps}$

Protocols Supported:

FTAM, Session (BCS full duplex), Transport Class 4, Internet Protocol, X.25

Organization Name: $\quad \mathrm{NCR}$

SSAP Selector:

NCR.FTAM $\quad=\Rightarrow \quad(4 e \quad 43 \quad 52 \quad 2 e \quad 46 \quad 54 \quad 414 d$ ) 
TSAP Selector: NSAP Address:

ACCUNET SNPA:

Point of Contact:

\subsection{OMNICOM, Inc:}

Point of Contact:

John W. Neumann

501 Church St., N.E.

Vienna, VA 22180

Organization ID: 21

4.18 Retix

Location:

Configuration:

Protocols:

Point of Contact:

Organization ID: 6

\subsection{UNISYS}

Point of Contact:

Anita Skelton 3151 Camino Ruiz Camarillo, CA 93010 (805) 987-9300

Organization ID: 18 


\subsection{TASC}

Point of Contact:

Organization ID:

19

\subsection{Wang}

\section{Organization: \\ Location: \\ Contact: \\ Address : \\ Phone: \\ Organization ID: Organization Name: System Identifyer: \\ FTAM AE Title: \\ PSAP Selector: \\ SSAP Selector: \\ TSAP Selector: \\ NSAP Address: \\ Network Connection: SNPA Address: \\ Network Connection: SNPA Address: \\ Availability: \\ Supported Protocols:}

Configuration:
Jonathan S. Katz

One Jacob Way

Reading, MA 01867

(617) 944-6850, Ext. 2282
WANG Laboratories, Inc.

Lowe11, Massachusettes

Joe Hielscher

One Industrial Avenue

Mailstop 014-A1B

Lowel1, MA 01851

617-967-1030

$0_{\text {WLILWL }}=9_{16}$

WLILWLVS1

FTAM

null ( $\mathrm{n} / \mathrm{A})$

$46544 I 4 D_{16}$

$0001_{16}$

$4700040009000100003607000000_{16}$ (OSI1)

ACCUNET Gateway

31346174301038 (OSII)

WANGPAC

00000036070000 (OSII) <-- Main System

9-5 Eastern Standard Time

FTAM-1, VARCRLF/UNDEF, BCS SesSion, TP-4 CLNP/X.25-80, X.25-80

VS 85 connected to WangPac Network Operation Center. WangPac gateways to AccuNet via an X.25 switch located in Lowell, MA. 
4.22 The Wollongong Group

Point of Contact:

Narayan Mohanram

1129 San Antonio Rd.

Palo Alto, CA 94303

Location:

Palo Alto, CA

Configuration:

3B15 processor

Protocols:

FTAM, BCS Session,

Transport (Class 4), CLNS

Organization ID: 8 


\section{PROGRAM OF WORK}

\subsection{INITIAL PROJECTS}

\section{1 .1 Initial Connectivity}

The first project is to provide connectivity among all of the OSINET companies.

This is viewed as a two-step process. The first step is for each company to connect, directly or via a gateway, to ACCUNET or WANGPAC and verify operation, i.e., connection establishment, data transfer, and connection termination.

The second step is to exercise the protocol suite described in section 2.1 of this document. This is to be done by executing a subset of the FTAM tests used for AUTOFACT 85 testing. The subset is to be determined by the Technical Comittee. Each company will run the FTAM tests with five other companies. The target date for completion of testing is May 4, 1987.

"Initial Connection" interoperability testing will be determined by completing testing with five (5) partners plus exchanging addressing and news information with the NIC.

(a) Cther testing can be conducted and recorded, but does not pertain to the "initial connection" interoperability completion criteria.

(b) It may be advantageous for OSINET participants to choose their partners.

(c) If participants decide to choose partners, they should inform INI before testing begins.

(d) Participants should attempt to test with different hardware/software systems, if they informally arrange test partners.

(e) All testing progress should continue to be reported to INI.

(f) INI will continue to assign test partners.

To ensure continued interoperability, participants are encouraged to perform regression testing when changes are made to their OSINET system.

\section{1 .2 NIC Services}

OSINET will provide Network Information Center services. 
5.1 .3 DoD Transition to the Use of OSI

The joint NBS, DCA, Navy, and Industry work on FTAM, MHS, VTP, and directory services as a step in the DOD transition to the use of OSI has been approved as an OSINET project.

\section{1 .41987 Product Exhibition}

A 1987 product exhibition proposed by GM, et al., has been conditionally approved as an OSINET project, subject to review of a detailed proposal.

\section{$\underline{5.1 .5 \times .400 \text { Message Handling Systems }}$}

OSINET can optionally be used by interested participants for the interoperability testing of electronic messaging protocols using the CCITT. X.400 Series of recommendations. It has been provisionally approved, subject to review of a detailed proposal, that testing will be based on the specifications of the NBS OSI Workshop SIG on X.400 specification, rev 1.0, as contained in NBSIR 86-3385.

\subsubsection{Nature of OSINET Messaging Project}

Participants in the OSINET Messaging project must provide network connectivity to the existing OSINET topology. Participation in the messaging project shall be an optional function for OSINET members.

An CSINET messaging participant may provide eitier a full end system (P1 and P2) or a message transfer service (P1 only) system. Both the PRMD-PRMD and PRMD-ADMD profiles will be utilized.

Initially, messaging participants will provide full messaging end-systems (PI and P2) and will provide one or more PRMDs; the PRMD-PRMD profile will be utilized. The PRMD-ADMD profile will be added when an OSINET member (or applicant) administration applies and an appropriate bridge (relay) to other CSINET messaging systems is provided. Participation as an intermediate PRMD or ADMD ( $\mathrm{PI}$ onIy) will be defined when requested by an OSINET member.

\subsubsection{Role of the Technical Committee}

The Technical Committee will collect and publish (in the OSINET agreements standing document) the X.400 messaging addressing information it feels is necessary to permit inter-member message exchange. This will include the subnetwork point of attachment (i.e., Accunet address), NSAP, T-selector, Sselector, PRMD name, MTA name, MTA password (if used) and the $O / R$ names of persons who may be sent mail. Where necessary, the Technical Committee shall insure that such elements as PRMD and MTA names are unique among members.

The Technical Comittee will make the above information available to members via the NIC. The TC will investigate maintaining NIC files listing the $O / R$ names of persons who may receive mail via OSINET at each member location. 
The Technical Committee will define and publish (as an appendix to the OSINET agreements standing document) a basic set of confidence tests designed to verify that mail can be successfully exchanged among OSINET messaging participants.

The Technical Committee will assign testing partners, such that each participant may execute the set of tests with at least five (5) other members.

The Technical Committee shall report on testing status to the Steering Committee.

The Technical Committee shall provide as liaison with the Workshop's X.400 SIG any questions, problems, or ambiguities detected in the messaging functional standard.

\subsubsection{Directory Services}

Directory Services, based on the joint ISO/CCITT standard and implementation agreements developed at the NBS/OSI Workshop, has been approved as an optional OSINET project. 


\section{POINTS OF CONTACT}

6.1 POINTS OF CONTACT FOR COMMITTEES

Jerry Mulvenna, Chair, OSINET Steering Committee, (301) 975-3622

Edward Strum, Chair, OSINET Technical Cormittee, (415) 885-7392

Jim Converse, liaison for MAP/TOP Steering Committee, (716) 726-1957

6.2 POINTS OF CONTACT FOR X.25 SERVICES

ACCUNET

WANGPAC
Steven Lind

AT\&T

Room 17-5361Cl

295 North Maple Avenue

Basking Ridge, NJ 07920

(201)221-2834

Joe Hielscher

Wang Laborabories, Inc.

One Industrial Avenue

Lowe 11, MA 01851

(617) 459-5000/967-1030 


\section{REFERENCES AND BIBLIOGRAPHY}

$\underline{\text { NBS }}$

NBSIR 86-3385-1: Implementation Agreements for Open Systems Interconnection Protocols, National Bureau of Standards, BIdg. 225, Rm. B217, Gaithersburg, MD 20899.

FIPS 107, Local Area Networks: Baseband Carrier Sense Multiple Accesswith Collision Detection Access Method and Physical Layer Specificationsand Link Layer Protocol, NTIS, U.S.Department of Comerce, 5285 PortRoyal Road, Springfield, VA 22161.

FIPS 100, Interface Between Data Terminal Equipment (DTE) and Data Circuit-Terminating Equipment (DCE) For Operation With Packet-Switched Data Communications Networks, NTIS, U.S. Department of Commerce, 5285 Port Royal Road, Springfield, VA 22161.

IEEE

IEEE Project 802, Local Area Network Standards, P802.2 Logical Link Control, November 1982 .

IEEE Project 802, Local Area Network Standards, IEEE Standard 802.4 Token Passing Bus Access Method and Physical Layer Specification.

IEEE Project 802, Local Area Network Standards, IEEE Standard 802.3 CSMA/CD Access Method and Physical Layer Specification.

The above documents may be obtained from IEEE Standards Office, 345 East 47 th Street, New York, N.Y. 10017.

ISO

Addendum to DIS 8473 Covering Provision of the Connectionless-Mode Network Service, ISO/TC97/SC 6/N3453.

Network Service Definition, DIS 8348, ISO/TC97/SC6 N2990.

Addendum to the Network Service Definition Covering Connectionless Data Transmission, DIS 8348 DAD1, N3152.

Addendum to the Network Service Definition Covering Network Layer Addressing, DP 8348 DAD2, N3134.

Internal Organization of the Network Layer, dp 8648.

Protocol for Providing the Connectionless Network Service, DIS 8473 N3154. 
Information Processing Systems - Open Systems Interconnection - Transport Service Definition, ISO IS8072, 1984.

Information Processing Systems - Open Systems Interconnection - Transport Protocol Specification, ISO IS8073, 1984.

Information Processing Systems - Open Systems Interconnection - Session Service Definition, ISO DIS8326, 1984.

Information Processing Systems - Open Systems Interconnection - Session Protocol Specification, ISO DIS8327, 1984.

Information Processing Systems - Open Systems Interconnection - File Transfer Access-and Management Part 1: General Description, ISO DP8571/1, TC97/SC16 N1669, February 1984.

Information Processing Systems - Open Systems Interconnection - File Transfer Access and Management Part II: The Virtual Filestore, ISO DP8571/2, TC97/SC16 N1670, February 1984.

Information Processing Systems - Open Systems Interconnection - File Transfer Access and Management Part III: Service Definition, ISDP8571/3, TC97/SC16 N1671, February 1984.

Information Processing Systems - Open Systems Interconnection - File Transfer Access and Management Part IV: Protocol Specification, ISODP8571/4, TC97/SC16 N1672, February 1984.

Data Commication - X.25 Packet Layer specification for Data Terminal Equipment, ISO/TC 97/SC6 N2641, ISO/DP 8208, 1983.

7-bit coded Character Set for Information Processing Interchange, IsO-646. 1973.

Information Interchange--Representation of Local Time Differentiais ISO-3307, 1975.

The above documents may be obtained from: Frances E. Schrotter, ANSI, ISO TC97/SC6 Secretariat, 1430 Broadway, New York, New York 10018

\section{CCITT}

X.25, Interface Between Data Terminal Equipment (DTE) and Data CircuitTerminating Equipment (DCE) for Terminals Operating in the Packet Mode on Public Data Networks.

X.400, Message Handling Systems: System Model-Service Elements.

X.40I, Message Handling Systems: Basic Service Elements and Optional User Facilities 
X.408, Message Handling Systems: Encoded Information Type Conversion Rules.

X.409, Message Handling Systems: Presentation Transfer Syntax and Notation. X.410, Message Handling Systems: Remote Operations and Reliable Transfer Server.

X.411, Message Handling Systems: Message Transfer Layer.

X.420, Message Handling Systems: Interpersonal Messaging User Agent Layer.

X.430, Message Handling Systems: Access Protocol for Teletex Terminals.

The above documents may be obtained from International Telecommunications Union, Place des Nations, $\mathrm{CH}$ 1211, Geneve 20 Switzerland.

\section{ATT COMMUNICATIONS}

DOC \#54010 - X.25 Interface Specification and Packet Switching Capabilities, January 1984 .

DOC \#54012 - X.75 Interface Specification and Packet Switching Capabilities, August 1984 .

See Section 3.1 for information on how to obtain these documents.

WANG

C/30 PSN X.25 Interface Specification, Release 3, Report No. 5500, November, 1983.

Packet Switch Node (PSN) 5.0 Release Note.

The above documents may be obtained from Joe Hielscher, Wang, One Industrial Avenue, Lowell, MA 01851 


\section{APPENDIX A: NETWORK ADDRESSING INFORMATION}

The NSAP address form chosen by OSINET participants follows.

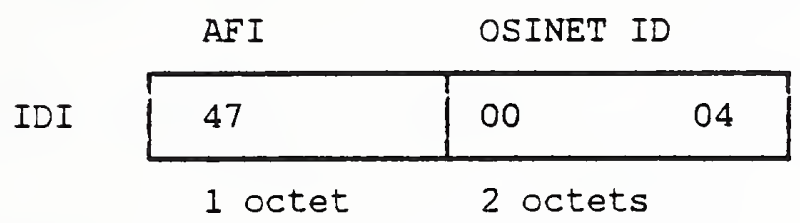

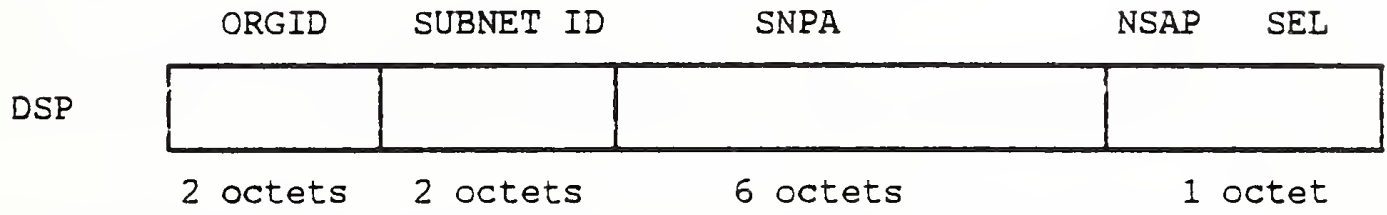

Routing on the X.25 backbone is based on the ORGID and possibly the subnet ID.

The SNPA is only meaningful to the destination subnetwork.

ISO has assigned OSINET an OSINET ID $=4$. NBS is the auministrative authority for Organization ID's. ORganization ID assignments are specified in cecimal form with company site configuration information in section 4. 


\section{APPENDIX B: FTAM INTEROPERABILITY TESTS}

The OSINET group has agreed that OSINET participants will run a standard set of tests which are a subset of the AUTOFACT FTAM tests to verify interoperability when they first join the network. Each OSINET participant will have a file named DIR.LIS which contains a list of other files which can be retreived. The presentation context will be VARCRLF. The tests to be run that follow are described in a language developed for the DEC FTAM implementations. OSINET interoperability testing will be between two FTAM implementations - the FTAM tester will not be used. Accordingly, the following information should be used as a guide to the FTAM functions that must be tested.

FRI013.COM ! Create and write file

set log fref $\$$ log: fri013. log

show time

\section{FTAM reference Test Scenario V0O3 FRIO13.COM}

ETAM Reference software runs as FTAM Initiator.

Establish FTAM connection regime.

Create, open, write data, close and deselect a file on the remote system.

The terminate the connection and disconnect the virtual circuit. (Assumes that the logical name FREFEMOTE translates to the target remote system.)

CONNECT/OUTBOUND/REMOTE=FREFEMOTE

!

SEND F_INITIATE_REQ ! f initiate request

RECEIVE F_INITIATE_P ${ }^{-}$! Wait for positive f_initiate response

SEND F_CREATE_REQ- ! Create remote file

/remote file=fri013.v -

local_file=frefsinfile:friol3.r -

/stream

RECEIVE F_CREATE_P

! Wait for positive f_select response 


\begin{tabular}{|c|c|c|}
\hline SEND & F_OPEN_REQ & ! f_open request \\
\hline $\begin{array}{l}\text { RECEIVE } \\
!\end{array}$ & F_OPEN_P & ! wait for open response \\
\hline $\begin{array}{l}\text { SEND } \\
!\end{array}$ & F_WRITE_REQ & ! f_write request \\
\hline SEND & F_TRANSER_END_REQ & ! Send f_transfer_end \\
\hline $\begin{array}{l}\text { RECEIVE } \\
!\end{array}$ & F_TRANSFER_END_P & ! Wait for f_transfer_end response \\
\hline SEND & F_TRANSFER_END_REQ & ! f_close request \\
\hline $\begin{array}{l}\text { RECEIVE } \\
!\end{array}$ & F_TRANSER_END_p & ! WĀIT for f_transfer_end response \\
\hline SEND & F_DESELECT_REQ & : Deselect remote file \\
\hline $\begin{array}{l}\text { RECEIVE } \\
!\end{array}$ & F_DESELECT_P & ! Wait for deselect response \\
\hline $\begin{array}{l}\text { DISCONNE } \\
!\end{array}$ & CT/OUTBOUND & \\
\hline
\end{tabular}

FRI007.COM ! Read attributes and read file

set log fref $\$$ log: frio07.log

show time

FTAM REFERENCE TEST SCENARIO V0O3 ERIOO7.COM

FTAM Reference software runs as FTAM Initiator.

Establish FTAM connection regime.

Select, open, read remote data, close and deselect a

file on the remote system

Then terminate the connection and disconnect the virtual circuit.

(Assumes that the logical name FREFEMOTE translates to the

target remote system.)

CONNECT/OUTBOUND/REMOTE=FREFEMOTE

!

\begin{tabular}{|c|c|c|}
\hline SEND & F INITIATE REQ & $f$ initiate request \\
\hline $\begin{array}{l}\text { RECEIVE } \\
\vdots\end{array}$ & F_INITIATE_p & Wait for positive f_initiate response \\
\hline Send & $\begin{aligned} \text { F_SELECT_REQ - } & ! \\
& \text { /remote_file }=f \\
& \text { /local_file }=f r \\
& \text { / stream }\end{aligned}$ & $\begin{array}{l}\text { Select remote file } \\
\text { fri007.v- } \\
\text { ref\$outfile:frio07.r - }\end{array}$ \\
\hline $\begin{array}{l}\text { RECEIVE } \\
!\end{array}$ & F_SELECT_P $\quad !$ & Wait for positive f_select response \\
\hline SEND & E_READ_ATTRIB_REQ & f_open request \\
\hline $\begin{array}{l}\text { RECEIVE } \\
!\end{array}$ & $F_{-}^{-}$READ_ATTRIB_P & wait for read attribute response \\
\hline SEND & F_OPEN_REQ & E_open request \\
\hline
\end{tabular}




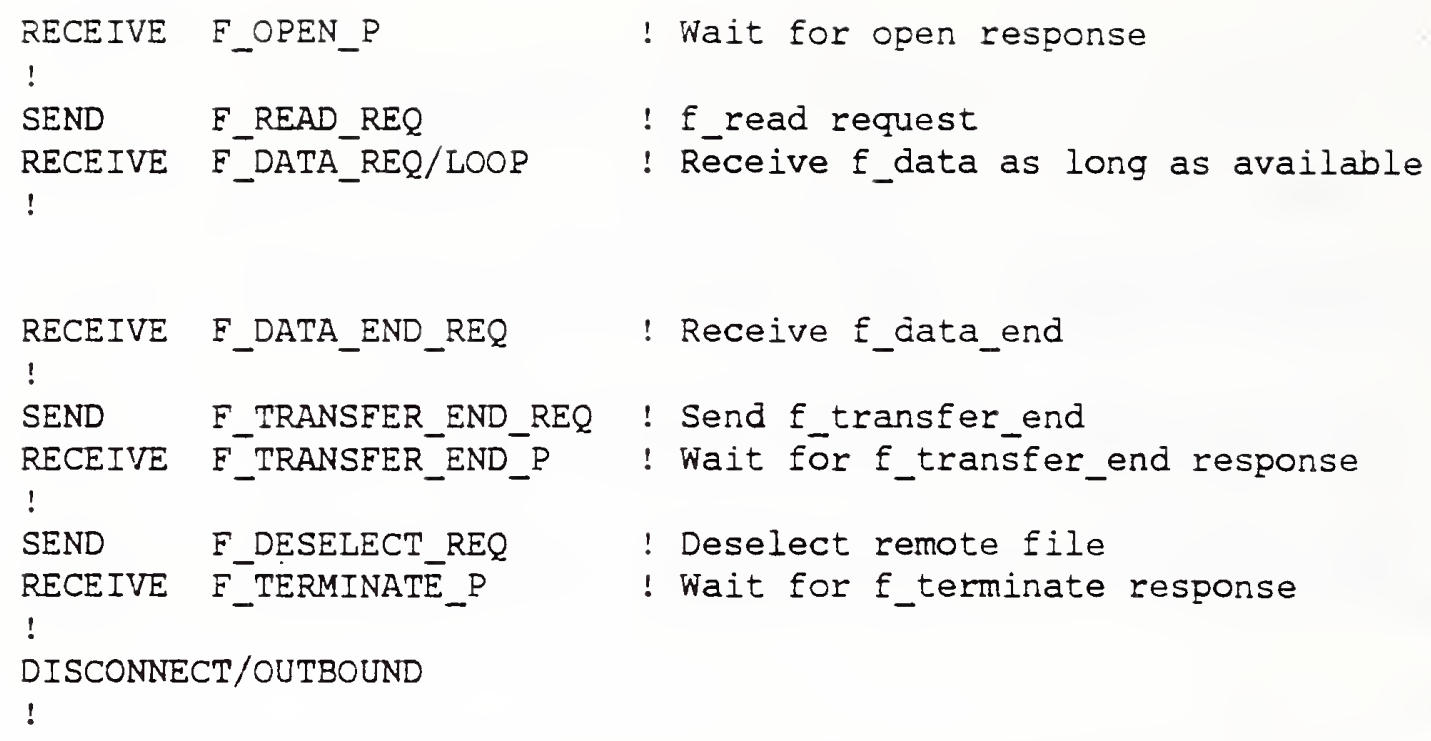




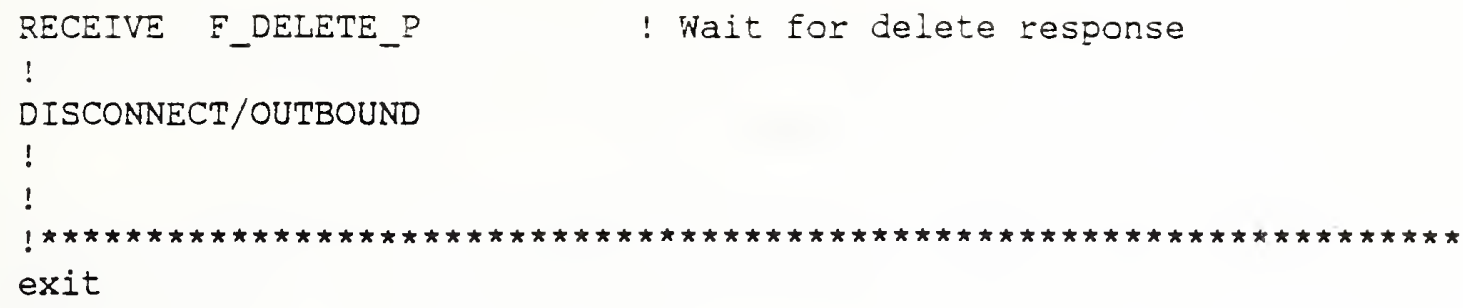


- 


\section{READER RESPONSE FORM}

You will receive the documents from the next OSINET Technical Committee meeting either by attending the next meeting or completing and returning the form below.

Please retain my name for OSINET Technical Committee mailings.

NAME :

ADDRESS :

PHONE:

Mail the above form to:

Carol Lemnah

National Bureau of Standards

Building 225, Room 3217

Gaithersburg, MD 20899 


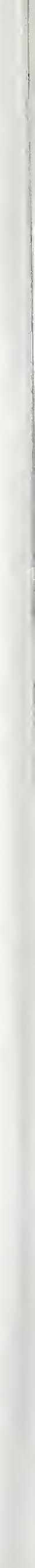


NBS.114A (REV. 2-8C)

U.S. OEPT. OF COMM.

BIBLIOGRAPHIC DATA

SHEET (See in structions)

1. PUBLICATION OR

2. Performing Organ. Report Nod 3. Publication Date REPORT NO.

NBSIR 86-3478-2

Yarch 1987

4. TITLE AND SUBTITLE

Implementation Agreements Among Participants of OSINET

5. $A \cup T H O R(S)$

Gerard F. Mulvenna

6. PERFORMING ORGANIZATION (If joint or other than NBS, see instructions)

7. Contracu Grant No.

NATIONAL BUREAU OF STANDARDS

U.S. DEPARTMENT OF COMMERCE

GAITHERSBURG, MD 20899

9. SPONSORING ORGANHZATICN NAME ANO COMPLETE ACORESS (Street, CII, StOTe, ZIP)

8. Type of Report \& Period Covered

10. SUPPLEMENTARY NOTES

Documenc describes a computer program; SF-185. FIPS Software Summary, is attached.

11. ABSTRACT (A 200-word or less foctual summory of most significant informotion. If document includes a significant bibliography or literature survey. mention it here)

This is a standing document reflecting agreements reached by the member companies and agencies of OSINET. The OSINET is a research network established for the purposes of developing prototype tests and test systems for Open Systems Interconnection network protocols, and other OSI-related research.

12. KEY WOROS (Six to twelve entries: alphabetical order: capitalize only proper names; and separate key words by semicolons) implementation agreements; Open Systems interconnection; OSINET; protocol testing; test tools; workshop

13. AVAILABILITY

Unlimited

14. NO. OF

PRINTED PAGES

F For Official Distribution. Do Not Release to NTIS

Order From Superintendent of Documents, U.S. Government Printing Office, Washington, D.C. 20402.

Order From Natıonal Technical Information Service (NTIS), Springfield, VA. 2216I

15. Price 

